\title{
Technical Note: Sensitivity of 1-D smoke plume rise models to the inclusion of environmental wind drag
}

\author{
S. R. Freitas ${ }^{1}$, K. M. Longo ${ }^{2}$, J. Trentmann ${ }^{3, *}$, and D. Latham ${ }^{4}$ \\ ${ }^{1}$ Center for Weather Forecasting and Climate Studies, INPE, Cachoeira Paulista, Brazil \\ ${ }^{2}$ Center for Space and Atmospheric Sciences, INPE, São José dos Campos, Brazil \\ ${ }^{3}$ University of Mainz, Mainz, Germany \\ ${ }^{4}$ USDA Forest Service, Montana, USA \\ *now at: German Weather Service, Offenbach, Germany
}

Received: 29 May 2009 - Published in Atmos. Chem. Phys. Discuss.: 7 July 2009

Revised: 16 December 2009 - Accepted: 11 January 2010 - Published: 21 January 2010

\begin{abstract}
Vegetation fires emit hot gases and particles which are rapidly transported upward by the positive buoyancy generated by the combustion process. In general, the final vertical height that the smoke plumes reach is controlled by the thermodynamic stability of the atmospheric environment and the surface heat flux released by the fire. However, the presence of a strong horizontal wind can enhance the lateral entrainment and induce additional drag, particularly for small fires, impacting the smoke injection height. In this paper, we revisit the parameterization of the vertical transport of hot gases and particles emitted from vegetation fires, described in Freitas et al. (2007), to include the effects of environmental wind on transport and dilution of the smoke plume at its scale. This process is quantitatively represented by introducing an additional entrainment term to account for organized inflow of a mass of cooler and drier ambient air into the plume and its drag by momentum transfer. An extended set of equations including the horizontal motion of the plume and the additional increase of the plume radius is solved to simulate the time evolution of the plume rise and the smoke injection height. One-dimensional (1-D) model results are presented for two deforestation fires in the Amazon basin with sizes of 10 and 50 ha under calm and windy atmospheric environments. The results are compared to corresponding simulations generated by the complex nonhydrostatic three-dimensional (3-D) Active Tracer High resolution Atmospheric Model (ATHAM). We show that the 1-
\end{abstract}

Correspondence to: S. R. Freitas (saulo.freitas@cptec.inpe.br)
D model results compare well with the full 3-D simulations. The 1-D model may thus be used in field situations where extensive computing facilities are not available, especially under conditions for which several optional cases must be studied.

\section{Introduction}

Biomass burning emits hot gases and particles which are transported upward by the positive buoyancy generated by the fire. Due to radiative cooling and the work done against the environment due to expansion during convective rise, there is a rapid decay of temperature above the burning area. Also, the interaction between the smoke and the environment produces eddies that entrain colder environmental air into the smoke plume, which cools and dilutes the plume and reduces buoyancy. The dominant characteristic is a strong upward flow with a moderate temperature excess from the ambient atmosphere. The final height that the plume reaches is controlled by the thermodynamic stability of the atmospheric environment and the surface heat flux release from the fire. Moreover, additional buoyancy may be gained from latent heat release of condensation and plays an important role in determining the effective injection height of the plume, that is, its terminal height. However, the occurrence of strong horizontal wind can lead to a bent-over and enhance lateral entrainment and can even prevent the plume's reaching the condensation level, particularly for small fires, severely impacting the injection height. This effect is shown by two photographs of the smoke plume rise produced from two

Published by Copernicus Publications on behalf of the European Geosciences Union. 


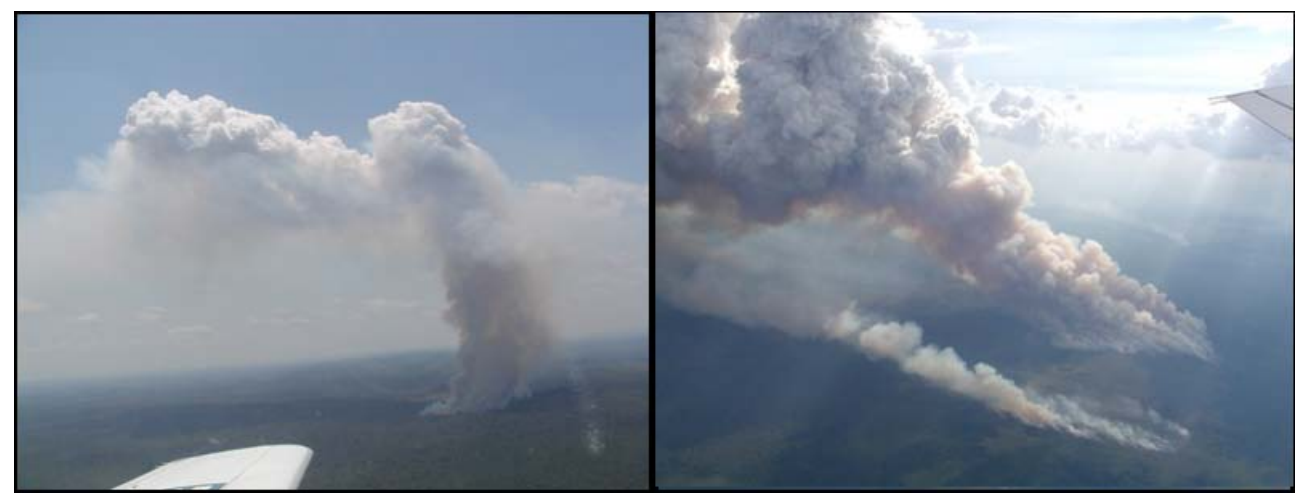

Fig. 1. Photographs of the smoke plume rise produced from two deforestation fires in the Amazon basin under calm (left) and windy (right) environments. Both photos were taken from aircraft. Note that size of the fires and the plume height differs substantially between the plumes. (Pictures taken by M. O. Andreae and M. Welling).

different deforestation fires in the Amazon basin (Fig. 1). The plume shown on the left moves upward with only a slight deviation from the vertical, indicating plume development in a calm environment. However, the plume on the right shows much stronger deflection from the vertical, an indication of a windy environment. Note that both plumes are capped by cumulus, indicating that cloud microphysics might have had a significant role in the plume development. The effect of ambient wind on the plume rise from volcanic sources has been studied by several authors. Graf et al. (1999) performed a set of sensitivity studies using a two-dimensional version of the Active Tracer High resolution Atmospheric Model (described here in Sect. 3.1) as a non-hydrostatic volcano plume model with explicit treatment of turbulence and microphysics. The authors applied this modeling system to simulate the impacts of environmental conditions on the vertical plume development. They found that, in general, a horizontal wind reduces the height reached by the plume. All environmental impacts were found to strongly depend on the intensity of the entrainment and, thus, on the quality of the calculated turbulence properties. Bursik (2001) applied a 1-D theoretical model of a plume to study the interaction between a volcanic plume and an ambient wind. $\mathrm{He}$ also shows that the enhanced entrainment from the wind decreases the plume rise height, mainly at altitudes with the high wind speeds of the polar jet. To the author's knowledge, no study on the impact of horizontal wind on the injection height of volcanic eruptions or wild fires is available that employs three-dimensional model simulations. However, observational and theoretical studies of volcanic eruptions (Ernst et al., 1994; Rose et al., 2003) and fire plumes (Cunningham et al., 2005; Cunningham and Linn, 2007) have shown the relevance of three-dimensional aspects for the dynamical evolution of such plumes. Hence, the results obtained from 1-D and 2-D simulations have to be interpreted with care. For the present work, ATHAM is used for 3-D simulations (see Sect. 3.1). In this paper we describe the improvement of the 1-D parameterization of the vertical transport of hot gases and particles emitted from vegetation fires, described in Freitas et al. (2007, hereafter F2007), to include the effects of environmental horizontal wind on transport and dilution of the smoke plume at its scale. This process is quantitatively represented by introducing an additional entrainment term to represent the organized inflow of the ambient air into the plume, as well as the drag on the plume by the external ambient wind. The extra entrainment enhances the in-plume mixing with the cooler and drier ambient air. The net effect on the dynamics is a reduction of the in-plume velocity in the vertical through momentum transfer to the entrained air mass; while horizontally, there is a strong acceleration in the nearby surface layer as well as in the layers with strong ambient wind shear. An extended set of equations, including the horizontal motion of the plume and increase of the plume radius, is now solved to simulate the time evolution of the plume rise and determine the final injection height.

In the methodology proposed by Freitas et al. (2006, 2007), the 1-D plume model is embedded in each column of 3-D low resolution atmospheric chemistry-transport models (the hosts) to provide interactively the smoke injection height, in which trace gases and aerosols, emitted during the flaming phase of the vegetation fires, are released and then transported and dispersed by the prevailing winds simulated by them.

This technical note is organized as follows. In Sect. 2, the methodology is described. Section 3, Part 1 discusses the dynamics and thermodynamics of the case studies. In parts 2 and 3, numerical simulations with 3-D ATHAM and the 1D plume models are introduced and compared. Conclusions are discussed in Sect. 4. 


\section{Model formulation}

The smoke plume rise associated to the biomass burning is parameterized using a simple one-dimensional timedependent entrainment plume model (Latham, 1994, F2007; hereafter 1-D PRM). Equations (1) to (7) introduce this 1-D PRM, modified to include the horizontal ambient air wind effect (we will focus on the new terms associated to the additional entrainment and the Eqs. (6) and (7), a more detailed description of the others terms and the original set of equations can be found in F2007):

$$
\begin{aligned}
\frac{\partial w}{\partial t}+w \frac{\partial w}{\partial z} & =\frac{1}{1+\gamma} g B-\left(\lambda_{\text {entr }}+\delta_{\text {entr }}\right) w \\
\frac{\partial T}{\partial t}+w \frac{\partial T}{\partial z} & =-w \frac{g}{c_{p}}-\left(\lambda_{\text {entr }}+\delta_{\text {entr }}\right)\left(T-T_{e}\right) \\
& +\left(\frac{\partial T}{\partial t}\right)_{\mu p}
\end{aligned}
$$

$\frac{\partial r_{\mathrm{v}}}{\partial t}+w \frac{\partial r_{\mathrm{v}}}{\partial z}=-\left(\lambda_{\text {entr }}+\delta_{\text {entr }}\right)\left(r_{\mathrm{v}}-r_{v_{\mathrm{e}}}\right)+\left(\frac{\partial r_{\mathrm{v}}}{\partial t}\right)_{\mu p}$

$$
\frac{\partial r_{\mathrm{c}}}{\partial t}+w \frac{\partial r_{\mathrm{c}}}{\partial z}=-\left(\lambda_{\text {entr }}+\delta_{\text {entr }}\right) r_{\mathrm{c}}+\left(\frac{\partial r_{\mathrm{c}}}{\partial t}\right)_{\mu p}
$$

$$
\begin{aligned}
\frac{\partial r_{\text {ice,rain }}}{\partial t}+w \frac{\partial r_{\text {ice, rain }}}{\partial z} & =-\left(\lambda_{\text {entr }}+\delta_{\text {entr }}\right) r_{\text {ice, rain }} \\
& +\left(\frac{\partial r_{\text {ice,rain }}}{\partial t}\right)_{\mu p} \\
& + \text { sedim }_{\text {ice,rain }}
\end{aligned}
$$

$\frac{\partial R}{\partial t}+w \frac{\partial R}{\partial z}=\left(\frac{3}{5} \lambda_{\text {entr }}+\frac{1}{2} \delta_{\text {entr }}\right) R$

Here $w, T, r_{\mathrm{v}}, r_{\mathrm{c}}, r_{\text {rain }}, r_{\text {ice }}$ are the vertical velocity, air temperature, water vapor, cloud, rain and ice mixing ratios, respectively, and are associated with in-plume air parcels. The velocity $u$ represents the horizontal velocity of the center of mass of the plume at level $z$. In Eq. (1) $\gamma$ is 0.5 and was introduced to compensate for the neglect of non-hydrostatic pressure perturbations (Simpson and Wiggert, 1969), $g$ is the acceleration due the gravity and $B$ is the buoyancy term related to the difference of temperature between the in-plume air parcel and its environment air and includes the downward drag of condensate water. In the equations above the index $e$ stands for the environmental value, all other variables refer to the center of mass of the plume. The term $\lambda_{\text {entr }}$ is the lateral entrainment given by

$\lambda_{\text {entr }}=\frac{2 \alpha}{R}|w|$ where $R$ is the radius of the plume and $\alpha=0.05$. In a windy environment, the relative horizontal motion between the plume and the ambient air enhances the lateral entrainment through a "collisional" process promoting an additional exchange of momentum, energy, water, trace gases and aerosols between both air masses. We assume instantaneous mixing between in-plume and ambient atmosphere properties inside the plume. To quantitatively include this process, we add an extra entrainment term called "dynamic entrainment" $\left(\delta_{\text {entr }}\right)$ formulated as

$\delta_{\mathrm{entr}}=\frac{2}{\pi R}\left(u_{e}-u\right)$

where all variables are as previously defined. The dynamic entrainment term is proportional to the difference between the magnitudes of the ambient atmosphere and plume horizontal velocities, because there is no dynamic entrainment when both masses are moving at the same speed. Also, $\delta_{\text {entr }}$ is inversely proportional to the plume radius size meaning that the bigger the plume, the less sensitive it is to this entrainment process. The derivation Eq. (9) is given in Appendix A.

Equation (1) is the vertical equation of motion. The new term $\left(-\delta_{\text {entr }} w\right)$ expresses the loss rate of in-plume vertical velocity due to momentum transfer to the ambient air mass entrained into the plume (environmental vertical velocity is assumed negligible when compared to the in-plume vertical velocity). Equations (2)-(5) express the first law of thermodynamics and mass continuity equations for water phases including the dynamic entrainment process. This process is included using the traditional bulk formulation, being expressed by the product of the entrainment rate and the difference between in-plume and ambient atmosphere values. Index $\mu p$ denotes the tendencies from cloud microphysics (see F2007 for a discussion about the cloud microphysics and sedimentation terms of these equations).

Equation (6) is introduced to represent the gain of horizontal velocity of the plume due to drag by the ambient air flow. It is the horizontal equation of motion and we assume that at the timescale of the plume rise both entrainment terms are main forcings for the horizontal acceleration. The horizontal entrainment terms are responsible for the bent-over plumes as seen in Fig. 1. The lower boundary condition for the solution $(u)$ of this equation is $u(z=0)=0$. From Eq. (6), with no ambient wind $\left(u_{e}(z)=0\right)$, the plume will develop only vertical motion, reducing to the original solution of F2007. Equation (7) represents the increase of plume radius size due to the entrainment, in this case amplified by the organized inflow of ambient air. In ambient air at rest, Eq. (7) reduces to the traditional formulation described in Turner (1973). The lower boundary condition for the solution of Eq. (7) is obtained from the fire size. 

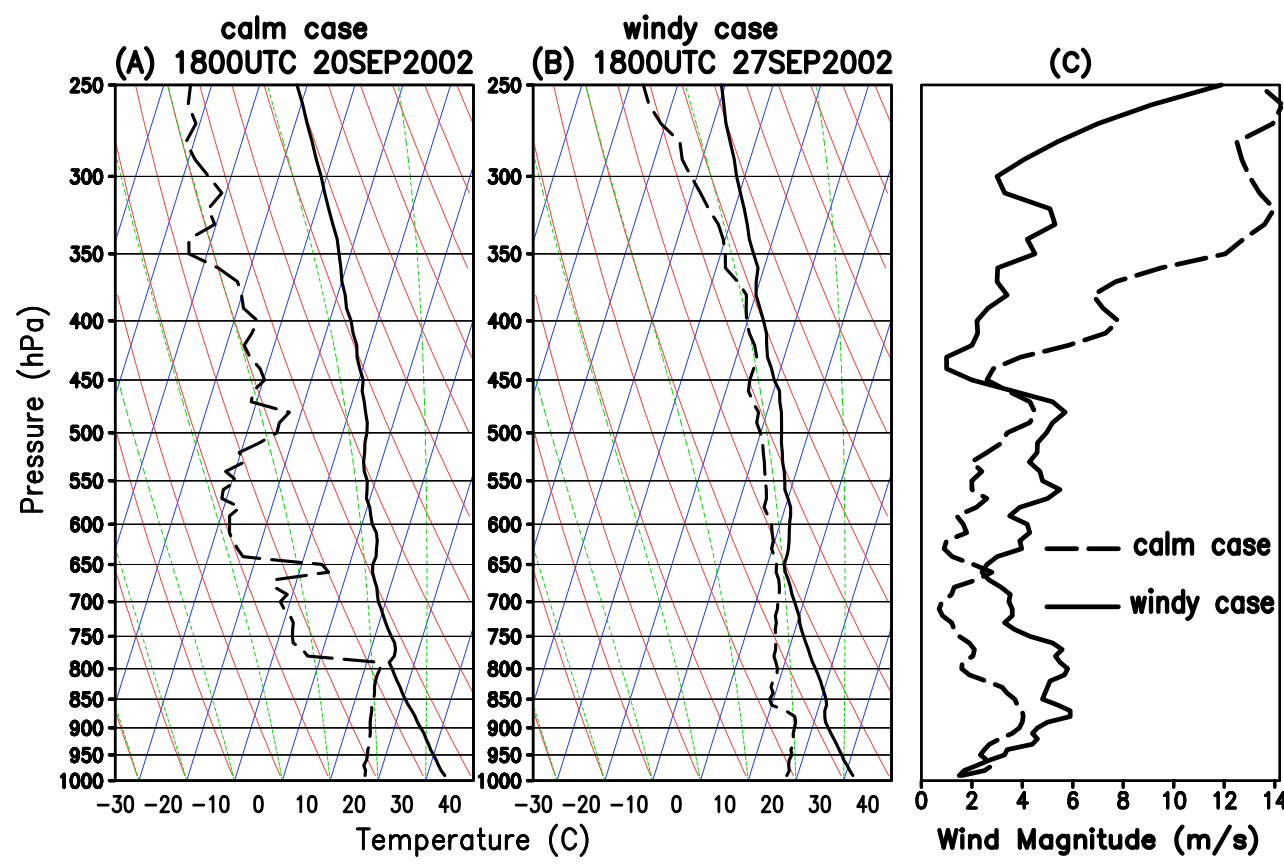

Fig. 2. Temperature (solid) and dew point temperature (dashed) profiles from a rawinsonde launched in Rondonia ( $11 \mathrm{~S}, 60 \mathrm{~W})$ shown by a skew $T-\log p$ diagram. Case (A) depicts the condition at 18:00 UTC on 20 September 2002, classified as the calm case. (B) is the windy case corresponding to 18:00 UTC on 27 September 2002. (C) Horizontal wind magnitude profiles of the calm (dashed) and windy (solid) cases obtained from the rawinsondes.

\section{Case studies and 1-D PRM comparisons with the ATHAM model}

In this section we provide an evaluation of the 1-D PRM model performance and sensitivity to the new formulation for simulating the smoke plume rise of Amazon basin deforestation fires, under different environmental conditions. Due the lack of observational data, we performed a set of numerical experiments of hypothetical prescribed fires and used the comprehensive 3-D ATHAM model to compare the 1-D model results and findings.

\subsection{Model descriptions and conditions of the simulations}

The numerical experiments were done under two selected thermodynamical situations. Figure 2 shows the two cases obtained from rawinsondes launched in the burning season of 2002 in the Amazon basin over a forested site and close to deforestation areas. Figure 2a depicts a typical atmospheric condition in the Amazon basin and central part of South America during the burning season at 18:00 UTC, normally the peak time of the diurnal cycle of basin fires. A rawinsonde, launched at 18:00 UTC on 20 September 2002, shows a strong thermal inversion around $800 \mathrm{hPa}$ with a very dry layer above. Figure $2 b$ shows the atmospheric condition one week later and in the same region, which is quite different.
There was a weaker thermal inversion around $870 \mathrm{hPa}$ and a much moister layer above compared with the previous case. In addition, these two cases also present a significant difference in the horizontal wind magnitude (Fig. 2c). For the first case, the mean magnitude is approximately $2 \mathrm{~m} \mathrm{~s}^{-1}$ from the surface to $500 \mathrm{hPa}$ while the latter has values of approximately 4 to $5 \mathrm{~m} \mathrm{~s}^{-1}$. Because of these characteristics, the cases are labeled as "calm" and "windy", respectively. Note also that there is strong wind shear in the first $1500 \mathrm{~m}$ for both situations, from 2 to $4 \mathrm{~m} \mathrm{~s}^{-1}$ and 2 to $6 \mathrm{~m} \mathrm{~s}^{-1}$ for calm and windy cases, respectively. The comparison between the two cases is interesting due to the different roles that cloud microphysics and ambient wind processes play on the position of the smoke injection layer.

Fires with sizes 10 and 50 ha were assumed for the model simulations and the prescribed heat flux was $80 \mathrm{~kW} \mathrm{~m}^{-2}$. The heating rate increases linearly in time from 0 to its prescribed value at time equal to $300 \mathrm{~s}$. To convert the heat flux to convective energy, the McCarter and Broido (1965) factor $(0.55)$ is used. The fraction of the total energy that is effectively available to the plume convection depends on the ambient and fuel conditions and is highly uncertain. Here we use a value in the middle of the commonly accepted range of 0.4-0.8 as described in Trentmann et al. (2002). The environmental condition for air pressure, temperature, water vapor mixing ratio, horizontal velocity and density were provided by the two rawinsondes described before. 
Table 1. Summary of the numerical experiments performed with each model. There are 8 experiments using the 1-D PRM and 4 using the ATHAM. Here ON/OFF means that the environmental horizontal wind drag was included $\left(u_{e}(z) \neq 0\right)$ and given by the rawinsondes data described above) or not $\left.\left(u_{e}(z)=0\right)\right)$, respectively, at simulation of the plume rise.

\begin{tabular}{|c|c|c|c|c|c|c|}
\hline \multirow{3}{*}{ Fire size } & \multicolumn{4}{|c|}{ Simulations with 1-D PRM } & \multicolumn{2}{|c|}{ Simulations with ATHAM } \\
\hline & \multicolumn{2}{|c|}{ Calm } & \multicolumn{2}{|c|}{ Windy } & \multirow[t]{2}{*}{ Calm } & \multirow[t]{2}{*}{ Windy } \\
\hline & $\begin{array}{l}\text { Environ. wind } \\
\text { effect }\end{array}$ & $\begin{array}{l}\text { Environ. wind } \\
\text { effect }\end{array}$ & $\begin{array}{l}\text { Environ. wind } \\
\text { effect }\end{array}$ & $\begin{array}{l}\text { Environ. wind } \\
\text { effect }\end{array}$ & & \\
\hline 10 ha & ON & OFF & ON & OFF & $X$ & $X$ \\
\hline 50 ha & ON & OFF & $\mathrm{ON}$ & OFF & $X$ & $X$ \\
\hline
\end{tabular}

The Active Tracer High resolution Atmospheric Model (Oberhuber et al., 1998) is a three-dimensional atmospheric plume model, which has been designed and employed for the simulation of strong convective events, e.g., volcanic eruptions (e.g., Graf et al., 1999; Herzog et al., 2003; Textor et al., 2003) and vegetation fires (e.g., Trentmann et al., 2002, 2006; Luderer et al., 2006). ATHAM solves the NavierStokes equation for a gas-particle mixture, based on external forcing including the transport of active tracers. Cloud microphysical processes are simulated using a two-moment scheme that predicts the numbers and mass mixing ratios of four hydrometeor classes and water vapor (Textor et al., 2006). The aerosol-cloud interactions are not considered in the simulations presented here.

Fire emissions are represented in ATHAM by prescribing emission fluxes into the lowest atmospheric model layer over specified fire grid boxes. In the present study, only fluxes of heat, moisture and aerosol particles are considered. The model simulations presented here were conducted on a stretched grid with a minimum horizontal and vertical model grid spacing of $50 \mathrm{~m} \times 50 \mathrm{~m} \times 50 \mathrm{~m}$ in the center and increasing grid spacing towards the edges of the model domain. The total model domain covered $15 \mathrm{~km} \times 15 \mathrm{~km} \times 23 \mathrm{~km}$ corresponding to $86 \times 86 \times 80$ grid boxes. The maximum time step was set to $1.5 \mathrm{~s}$, the minimum time step was determined dynamically by the Courant-Friedrich-Lewy (CFL) criterion.

Evaluating the quality of ATHAM simulations with reality is a challenging task. The ATHAM model results substantially depend on the initial and boundary conditions of the atmosphere and the fire. While the atmospheric conditions are usually known within an acceptable accuracy, fire information (e.g., the amount of biomass burned within a known period of time) is rarely available. ATHAM results have been evaluated for two vegetation fires, for which some information on the fuel was available: the Quinault Fire at the US Pacific Coast and the Chisholm fire in Canada. In both cases, ATHAM was able to realistically simulate the evolution of the plume and its injection height (Trentmann et al., 2002, 2006).

The 1-D PRM was run using a constant grid space resolution of $100 \mathrm{~m}$ with a top at $20 \mathrm{~km}$ height. The model time step was dynamically calculated following the CFL stability criterion, not exceeding $5 \mathrm{~s}$. The microphysics is resolved using time splitting ( $1 / 3$ of dynamic time step). The upper boundary condition is defined as a Rayleigh friction layer with $60 \mathrm{~s}$ timescale. Typically, steady state is reached within $50 \mathrm{~min}$, this number being the upper limit of the time integration. The final rise of the plume (the plume height top) is determined by the height for which the vertical velocity of the in-plume air parcel is less than $1 \mathrm{~ms}^{-1}$.

In total, we performed twelve simulations. Four of them were conducted using the ATHAM model, which was initialized with the atmospheric conditions described above and fire sizes of 10 and 50 ha. For simulations which used the 1D PRM configuration, we performed four additional simulations besides those with the same configuration as ATHAM. These four simulations did not account for the effect of environmental horizontal wind drag. In these simulations, the horizontal ambient wind was set to zero $\left(u_{e}(z)=0\right)$. Table 1 summarizes the simulations.

\subsection{Description and results of the ATHAM model runs}

Figure 3 presents the horizontally averaged vertical aerosol mass profile at different times after model start for a fire with a size of 10 ha and a heat flux of $80 \mathrm{~kW} \mathrm{~m}^{-2}$ for the calm (panel a) and the windy cases (panel b). For the calm case, the main simulated injection height occurs slightly below $4 \mathrm{~km}$, while the outflow height of the windy case takes place around $1.5 \mathrm{~km}$. The differences in the outflow height are determined by the different atmosphere thermodynamic stabilities of the profiles (Fig. 2a and b) and the differences in the wind profiles (Fig. 2c). The windy case is characterized by a stronger horizontal wind between the 950 and the $570 \mathrm{hPa}$ levels than in the calm case. In Fig. $3 \mathrm{~b}$ results from four simulation times are presented demonstrating that the emission height reaches an equilibrium level after $30 \mathrm{~min}$ of simulation. Figure $3 \mathrm{c}$ and d show results from ATHAM simulations assuming a fire with a size of 50 ha. As expected, in both cases the injection height reaches higher altitudes than in the case of the 10 ha fire. The thermodynamic structures of the profiles show a narrow vertical extension of the aerosols 

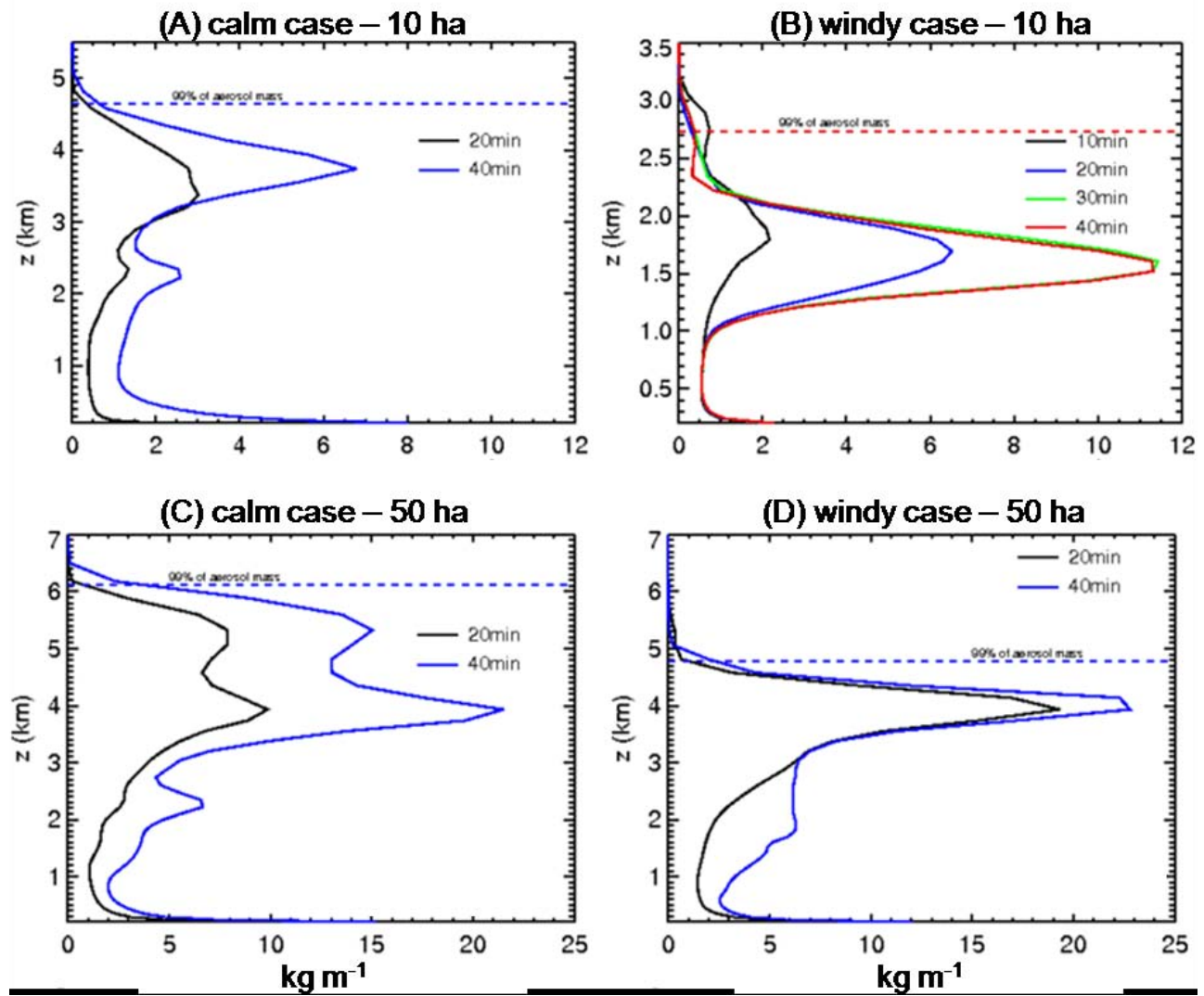

Fig. 3. Horizontally averaged vertical aerosol mass profile $\left(\mathrm{kg} \mathrm{m}^{-1}\right)$ as simulated by the ATHAM model for the calm (A), (C) and windy (B), (D) cases. Model results for a fire with size of 10 ha (A, B) and 50 ha (C, D). Note that the vertical axis uses different ranges for the height $z$.

in the windy case near $4 \mathrm{~km}$, while the aerosol is spread between 4 and $6 \mathrm{~km}$ in the calm case. In both cases, the atmospheric stability is lower in the windy case, so the plume should be higher, but due to lateral wind effects it is bended to the side, at the expense of vertical motion with stronger mixing with the ambient air properties.

\subsection{Model results of 1-D PRM runs and comparison with ATHAM simulations}

In this section 1-D PRM model results are discussed and compared with the 3-D ATHAM simulations. In order to compare the results from PRM to those from ATHAM, we introduced the parameter vertical mass distribution (VMD) which is parameterized from the vertical wind profile simulated by PRM model (see Appendix B). The way this quantity is defined provides the injection layer estimated by the 1D simulation. Obviously, the injection layer is not explicitly simulated in 1-D model as it is in 2-D or 3-D cloud resolving models such as ATHAM and needs to be parameterized. The VMD provides a probability vertical mass distribution as a function of the simulated 1-D vertical velocity profile.

\subsubsection{Smaller fires $\mathbf{- 1 0}$ ha size}

Figure $4 \mathrm{a}$ and $\mathrm{b}$ show the 1-D PRM model steady state solutions in the calm and windy ambient cases, respectively. We assumed identical fires burning tropical forest areas with a heat flux of $80 \mathrm{~kW} \mathrm{~m}^{-2}$ (as stated before) and a size of $10 \mathrm{ha}$ under both ambient conditions. The vertical velocity (W, $\mathrm{m} \mathrm{s}^{-1}$ ) and vertical mass distribution (VMD, \%) profiles are shown. Both panels also introduce the model results considering a no-wind hypothesis by setting $u_{e}(z)=0$, as described in Sect. 3.1.

For the calm case, panel (a) of Fig. 4, 1-D PRM predicts a plume top near 4 and $5 \mathrm{~km}$ including or not the ambient atmosphere wind effect, respectively. Thus, in this case, the enhanced entrainment reduced the plume top height by around $1 \mathrm{~km}$. The plume top height predicted by ATHAM (Fig. 3a) was $\sim 4.8 \mathrm{~km}$ with the aerosol mass injection layer localized approximately between 3 and $4.5 \mathrm{~km}$ (showed at Fig. 4 as grey filled rectangles). The vertical mass distribution without dynamic entrainment coincides well with the ATHAM results, being somewhat wide and deeper. The 1D PRM model, with dynamic entrainment caused by the 

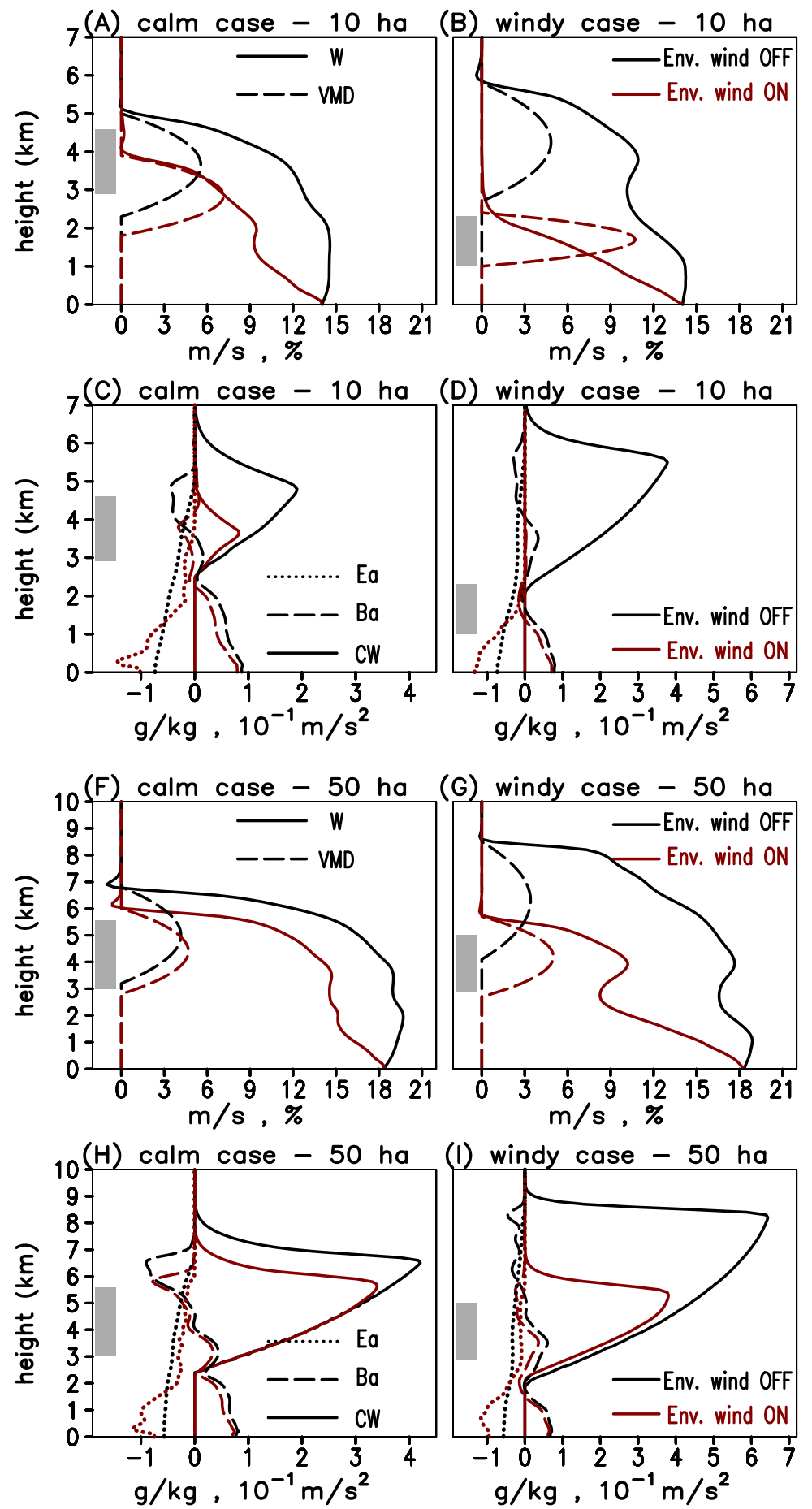

Fig. 4. 1-D PRM model results for the calm and windy cases. For the calm condition, (A) and (C) show the results for a fire size of 10 ha; while $(\mathbf{F})$ and $(\mathbf{H})$ refers to the 50 ha size. The results for the windy case are in (B) and (D) (10 ha) and (G) and (I) (50 ha). The quantities are: vertical velocity $\left(W, \mathrm{~m} \mathrm{~s}^{-1}\right)$, vertical mass distribution (VMD, \%), entrainment acceleration $\left(E_{\mathrm{a}}, 10^{-1} \mathrm{~m} \mathrm{~s}^{-2}\right)$, buoyancy acceleration $\left(B_{\mathrm{a}}\right.$, $10^{-1} \mathrm{~m} \mathrm{~s}^{-2}$ ), and total condensate water $\left(\mathrm{CW}, \mathrm{g} \mathrm{kg}^{-1}\right)$. Model results considering the environmental wind drag are in red color. Black color depicts the simulations disregarding this effect. The grey rectangles indicate the main injection height simulated by the ATHAM model. 
relative motion between the smoke plume and the ambient air, predicts a lower layer, with approximately the upper half inside the ATHAM injection layer and the lower half below that.

To better understand the role of the dynamic entrainment, we show at Fig. $4 \mathrm{c}$ the total condensate water (CW), buoyancy acceleration $\left(B_{\mathrm{a}}\right)$ and entrainment acceleration $\left(E_{\mathrm{a}}\right)$ for the cases discussed before. $\mathrm{CW}$ is in mixing ratio $\left(\mathrm{g} \mathrm{kg}^{-1}\right)$ and refers to the total condensed water (liquid, rain and ice). The buoyancy and entrainment accelerations $\left(\mathrm{m} \mathrm{s}^{-2}\right)$ are defined respectively by:

$\mathrm{B}_{\mathrm{a}}=\frac{1}{1+\gamma} g \mathrm{~B}$

$\mathrm{E}_{\mathrm{a}}=-\left(\lambda_{\text {entr }}+\delta_{\text {entr }}\right) w$

where the symbols on the right side were already defined before. The balance between these two terms provides the net vertical acceleration of the in-plume air parcels. With no dynamic entrainment in the model formulation, the plume is capped by a cumulus with a total condensate water of $\sim 2 \mathrm{~g} \mathrm{~kg}^{-1}$ near $5 \mathrm{~km}$ height. Dynamic entrainment strongly reduces the cumulus properties, not only in terms of the total condensed water (maximum $\sim 1 \mathrm{~g} \mathrm{~kg}^{-1}$ ) but also the cloud volume. In terms of the buoyancy acceleration, the dynamic entrainment reduces its magnitude due to enhanced entrainment of drier air. On the other hand, the entrainment acceleration is increased (in magnitude) in the lower levels, due to additional dynamic entrainment. At upper levels, the magnitude of $\mathrm{E}_{\mathrm{a}}$ decreases because $\delta_{\text {entr }}$ is smaller (since $u$ is approximately $u_{e}$ ) and at the same time the lateral entrainment is smaller due the larger horizontal size of the plume. The net effect of $\delta_{\text {entr }}$ is to reduce the vertical velocity for the entire plume column and its top height.

The windy ambient case is discussed as follows. Profiles of vertical velocity and vertical mass distribution are shown in Fig. 4b. In this case, the impact of the dynamic entrainment is greatly pronounced. Not taking account the drag by the horizontal ambient wind, results on a predicted plume top height at $\sim 5.8 \mathrm{~km}$ with a VMD between 2.8 and $5.8 \mathrm{~km}$ by 1-D PRM. However, the plume top height predicted by ATHAM (Fig. 3b) was $\sim 2.5 \mathrm{~km}$ with the aerosol mass detrainment layer (represented at Fig. 4b by the grey rectangle) localized approximately between 1 and $2.3 \mathrm{~km}$. In this case the predicted 1-D PRM plume top height and VMD totally disagree with the corresponding ATHAM model results. On the other side, with the dynamic entrainment included, 1-D PRM predicts a much lower plume top height around $\sim 2.6 \mathrm{~km}$ with VMD between 1 and $2.5 \mathrm{~km}$, and now the agreement with ATHAM is significantly improved.

For this case, the condensed water and accelerations are shown in Fig. 4d. Because the ambient air is moister in the windy case, when comparing with the calm case, not including the dynamic entrainment, the plume is capped by a bigger cumulus with the $\mathrm{CW}$ of $\sim 4 \mathrm{~g} \mathrm{~kg}^{-1}$ at $5.5 \mathrm{~km}$ height.
However, because of the stronger deceleration caused by the windy environment and efficient mixing with drier and cooler ambient air, the plume is prevented to reach the lifting condensation level. Consequently, there is no additional buoyancy gained from latent heat release which would induce further vertical displacement of the in-plume air parcels and higher plume top height. In this case, no clouds are formed at top of the plume $(\mathrm{CW} \sim 0)$. Both processes explain the much lower plume top height and injection layer presented in the windy case.

\subsubsection{Bigger fires $\mathbf{- 5 0}$ ha size}

The 1-D PRM model simulations for bigger fires are discussed here. Figure $4 \mathrm{f}$ and $\mathrm{i}$ introduce the results for bigger fires with size of 50 ha. All other settings remain the same as in the previous cases. The larger size of the fire promotes stronger updrafts and higher clouds tops, similar to ATHAM results. For the calm case, the vertical velocity and VMD profiles are shown in panel (f). The difference in the cloud top height caused by dynamic entrainment is about $1 \mathrm{~km}$ (from 7 to $6 \mathrm{~km}$ ). The cloud top predicted by ATHAM (Fig. $3 \mathrm{c}$ ) was $\sim 6 \mathrm{~km}$ with the aerosol mass detrainment layer localized approximately between 3 and $5.8 \mathrm{~km}$. The results of the 1-D PRM with the dynamic entrainment present a better agreement with ATHAM simulation in terms of the predicted cloud top as well as the injection layer height and depth, as described by the VMD quantity.

Figure $4 \mathrm{~g}$ shows the results for the windy ambient case. As in the case of the 10 ha fire, including dynamic entrainment causes much larger changes in the simulated plume rise; the plume top height drops from 8.5 to $5.8 \mathrm{~km}$, a difference of $2.7 \mathrm{~km}$. The vertical mass distribution not including the dynamic entrainment is centered at $6.5 \mathrm{~km}$ extending from 4 to $8.5 \mathrm{~km}$. Due to the enhanced horizontal entrainment associated with relative motion between ambient and the plume, the vertical mass distribution center drops to $4.2 \mathrm{~km}$ extending from 2.8 to $5.8 \mathrm{~km}$. From ATHAM simulation (Fig. 3d), the predicted plume top of this case is around $4.9 \mathrm{~km}$ with the main detrainment aerosol layer localized between $\sim 2.9$ and $4.9 \mathrm{~km}$. Therefore, similar to the calm case, including the dynamic entrainment results in a much better agreement with the 3-D model simulations. 1-D PRM results and discussion of the simulated $\mathrm{CW}, \mathrm{B}_{\mathrm{a}}$ and $\mathrm{E}_{\mathrm{a}}$ for the 50 ha fire are very similar to the presented for the 10 ha fire size and are shown at panels (h) and (i). However, in this case the smoke plume is capped by a cumulus (panel i), unlike the calm case (panel d), indicating that the smoke plume reached the condensation level due to the stronger initial updraft caused by the larger fire size and the smaller entrainment rates. 


\section{Conclusions}

We have extended the 1-D cloud model described in F2007 to include the effect of the ambient atmosphere wind on the smoke plume rise development associated with vegetation fires. This process is represented by an additional entrainment term proportional to the difference between horizontal wind speeds of the center of mass of the plume and the ambient air. We have shown that this effect has an important impact on the definition of the plume top and the effective injection heights mainly for smaller fires under moist and windy situations. To verify the reliability of the physical representation of 1-D model, its results are compared with ones produced using the complex non-hydrostatic 3-D ATHAM model. Our findings suggest that the extended 1-D model can generate feasible simulations when compared to the 3-D model.

There are few observational data related to fires to be used to evaluate this 1-D PRM. So far, we identified two well documented cases: the 1994 Quinault and 2001 Chisholm fires. Detailed studies comparing the performance of 1-D PRM on simulating the plume top and injection heights of these fires will appear on upcoming paper.

The new formulation, when embedded in 3-D regional or global transport models to determine the vertical mass detrainment layer of smoke associated to vegetation fires, should improve the simulation of vertical distribution, transport and dispersion of aerosols and trace gases, mainly in areas dominated by small fires, as in savannas, pasture or cropland, and/or in a windy environment where the dynamic entrainment processes dominate the plume-environment horizontal mixing.

The new information needed by the extended formulation is the horizontal ambient wind, which is routinely simulated by the large scale 3-D host models. Therefore this new feature is easily implemented and the impact of wind-generated dynamic entrainment process on regional and global smoke distribution predicted. In addition, the vertical mass distribution provides a way that 1-D cloud models can simulate not only the cloud top but also the actual mass detrainment layers. These are the fundamental quantities needed to determine the emission source field resulting of vegetation fires to be used in the 3-D host large scale transport models.

\section{Appendix A}

\section{The dynamic entrainment formulation}

Consider a cylindrical volume of radius $R$ and depth $\Delta z$ (see Fig. A1). The horizontal mass flux $\left(f_{\mathrm{h}}\right)$ within the plume is given by

$f_{\mathrm{h}}=\rho_{e}\left(u_{e}-u\right)$

where $\rho_{e}$ is the ambient air density and $u_{e}$ and $u$ were defined above. Therefore, the mass gained by this plume layer during

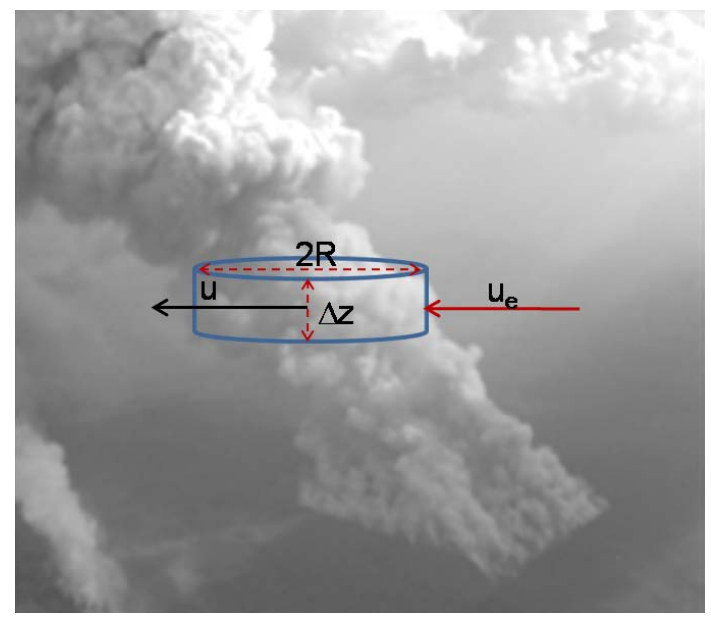

Fig. A1. The description of the dynamic entrainment rate formulation (picture taken by M. Welling).

the time $\Delta t$ is

$\Delta m=f_{\mathrm{h}}(2 R \Delta z) \Delta t=\rho_{e}\left(u_{e}-u\right)(2 R \Delta z) \Delta t$

The definition of the mass entrainment rate is

$$
\begin{aligned}
\delta_{\text {entr }} & =\frac{1}{m} \frac{\Delta m}{\Delta t} \\
& =\frac{1}{\pi R^{2} \Delta z \rho_{\text {cloud }}} \frac{\rho_{e}\left(u_{e}-u\right)(2 R \Delta z) \Delta t}{\Delta t}
\end{aligned}
$$

where $\rho_{\text {cloud }}$ is the in-cloud air density. Assuming that

$\rho_{\text {cloud }} \approx \rho_{e}$,

we finish with the following expression for the dynamic entrainment

$\delta_{\mathrm{entr}}=\frac{2}{\pi R}\left(u_{e}-u\right)$.

\section{Appendix B}

\section{The vertical mass distribution (VMD) definition}

The definition is based on the well established premise that the main detrainment (injection) mass layer of cumulus convection is situated close to the cloud top. The vertical mass distribution VMD is parameterized from the vertical wind profile, in order to compare the results from 1-D PRM to those from ATHAM. ATHAM model results for the vertical velocity profiles (not shown) demonstrated that the main smoke injection layer, defined in terms of the horizontally averaged mass distribution (see Fig. 3), is indeed situated in the outflow region close to the plume top. Here we parameterize the outflow region as the upper half part of the plume. The upper part is defined beginning at the vertical level where 
the in-plume vertical velocity starts to decrease $\left(z_{i}\right)$ until the level where it is less than $1 \mathrm{~m} \mathrm{~s}^{-1}\left(z_{f}\right)$. Based on this definition, the vertical mass distribution is defined as follows:

(a) from the 1-D PRM steady state vertical velocity profile, the upper half part of the cumulus is determined in terms of the heights $z_{i}$ and $z_{f}\left(z_{f}>z_{i}\right)$;

(b) a parabolic function of the height $z$ with roots at $z_{i}$ and $z_{f}$ is defined;

(c) the function is then normalized to 1 in the interval $\left[z_{i}\right.$, $\left.z_{f}\right]$.

Acknowledgements. We acknowledge partial support of this work by CNPq (302696/2008-3, 309922/2007-0) and by the Max Planck Society (MPG). J. T. thanks Stephan Eto for conducting the ATHAM model simulations. The authors thank the anonymous reviewer for the constructive comments and helpful suggestions.

Edited by: Y. Balkanski

\section{References}

Bursik, M.: Effect of wind on the rise height of volcanic plumes, Geophys. Res. Lett., 28(18), 3621-3624, 2001.

Cunningham, P., Goodrick, S. L., Hussaini, M. Y., and Linn, R. R.: Coherent vortical structures in numerical simulations of buoyant plumes from wildland fires, Int. J. Wildland Fire, 14, 61-75, 2005.

Cunningham, P. and Linn, R. R.: Numerical simulations of grass fires using a coupled atmosphere-fire model: Dynamics of fire spread, J. Geophys. Res., 112, D05108, doi:10.1029/2006JD007638, 2007.

Ernst, G. G. J., Davis, J. P., and Sparks, R. S. J.: Bifurcation of volcanic plumes in a crosswind, Bull Volcanol, 56, 159-169, 1994.

Freitas, S. R., Longo, K. M., and Andreae, M. O.: Impact of including the plume rise of vegetation fires in numerical simulations of associated atmospheric pollutants, Geophys. Res. Lett., 33, L17808, doi:10.1029/2006GL026608, 2006.

Freitas, S. R., Longo, K. M., Chatfield, R., Latham, D., Silva Dias, M. A. F., Andreae, M. O., Prins, E., Santos, J. C., Gielow, R., and Carvalho Jr., J. A.: Including the sub-grid scale plume rise of vegetation fires in low resolution atmospheric transport models, Atmos. Chem. Phys., 7, 3385-3398, 2007, http://www.atmos-chem-phys.net/7/3385/2007/.
Graf, H.-F., Herzog, M., Oberhuber, J. M., and Textor, C.: The effect of environmental conditions on volcanic plume rise, J. Geophys. Res., 104(D20), 24309-24320, 1999.

Herzog, M., Oberhuber, J. M., and Graf, H.-F.: A Prognostic Turbulence Scheme for the Nonhydrostatic Plume Model ATHAM, J. Atmos. Sci., 60, 2783-2796, 2003.

Latham, D.: A one-dimensional plume predictor and cloud model for fire and smoke managers, General Technical Report INTGTR-314, Intermountain Research Station, USDA Forest Service, November, 1994.

Luderer, G., Trentmann, J., Winterrath, T., Textor, C., Herzog, M., Graf, H. F., and Andreae, M. O.: Modeling of biomass smoke injection into the lower stratosphere by a large forest fire (Part II): sensitivity studies, Atmos. Chem. Phys., 6, 5261-5277, 2006, http://www.atmos-chem-phys.net/6/5261/2006/.

McCarter, R. and Broido, A.: Radiative and convective energy from wood crib fires, Pyrodinamics, 2, 65-85, 1965.

Oberhuber, J. M., Herzog, M., Graf, H.-F., and Schwanke, K.: Volcanic plume simulation on large scales, J. Volcanol. Geotherm. Res., 87, 29-53, 1998.

Rose, W. I., Gu,Y., Watson, I. M., et al.: The February-March 2000 Eruption of Hekla, Iceland from a Satellite Perspective, in Volcanism and Earth's Atmosphere, Geophys. Monogr. Ser., 139, edited by: Robock, A. and Oppenheimer, C., 107-132, AGU, Washington, D. C., 2003.

Simpson, J. and Wiggert, S.: Models of precipitating cumulus towers, Mon. Weather Rev., 97, 471-489, 1969.

Textor, C., Graf, H.-F., Herzog, M., and Oberhuber, J. M.: Injection of gases into the stratosphere by explosive volcanic eruptions, J. Geophys. Res., 108(D19), 4606, doi:10.1029/2002JD002987, 2003.

Textor, C., Graf, H. F., Herzog, M., Oberhuber, J. M., Rose, W. I., and Ernst, G. G. J.: Volcanic particle aggregation in explosive eruption columns, Part I: Parameterization of the microphysics of hydrometeors and ash, J. Volcanol. Geotherm. Res., 150, 359377, 2006.

Trentmann J., Andreae, M. O., Graf, H.-F., Hobbs, P. V., Ottmar, R. D., and Trautmann, T.: Simulation of a biomass-burning plume: Comparison of model results with observations, J. Geophys. Res., 107(D2), 4013, doi:10.1029/2001JD000410, 2002.

Trentmann, J., Luderer, G., Winterrath, T., Fromm, M. D., Servranckx, R., Textor, C., Herzog, M., Graf, H.-F., and Andreae, M. O.: Modeling of biomass smoke injection into the lower stratosphere by a large forest fire (Part I): reference simulation, Atmos. Chem. Phys., 6, 5247-5260, 2006, http://www.atmos-chem-phys.net/6/5247/2006/.

Turner, J. S.: Buoyancy effects in fluids, Cambridge Univ. Press, Cambridge, 368 pp., 1973. 